\title{
OS CICLOS E A PROGRESSÃO CONTINUADA NA OPINIÃO DE PAIS E ALUNOS'
}

\author{
Márcia Aparecida Jacomini*
}

RESUMO: O objetivo deste artigo é analisar a opinião de pais e alunos sobre os ciclos e a progressão continuada na Rede Municipal de São Paulo. A pesquisa de campo foi realizada em duas escolas durante o ano letivo de 2005. Os dados foram coletados por meio de visitas semanais às escolas e entrevistas com 28 pais e 28 alunos, das duas escolas, e organizados em categorias temáticas, de acordo com Bardin (2004). A análise dos dados mostra que o conhecimento dos entrevistados sobre a organização do ensino municipal refere-se à forma de progressão dos alunos e eles não sabem o que é um ensino organizado em ciclos. A maioria dos entrevistados disse ser contrária à progressão continuada porque acredita que, sem a reprovação anual, os alunos serão promovidos sem saber e não estudam. Observou-se que o fato de o ensino municipal de São Paulo não estar organizado em ciclos, tal como foi concebido na proposta inicial, A ausência de um ensino em ciclos na cidade de São Paulo parece influenciar a oposição de pais e alunos à progressão continuada.

Palavras-chave: Ciclos; Pais; Alunos.

\section{SCHOOLING CYCLES AND CONTINUOUS ASSESSMENT IN PARENTS AND STUDENTS' OPINION}

ABSTRACT: The goal of this paper is to analyze parents and students' opinion on both the schooling cycles and the continuous assessment adopted by the Educational Public System of São Paulo City. The research was conducted in two schools during the school year of 2005. The data were collected in the course of weekly visits to both schools as well as from interviews carried out with 28 parents and 28 students from these schools, and, after that, sorted into thematic categories, according to Bardin (2004). The analysis of the data shows that the knowledge the interviewees have about the organization of the educational system in São Paulo city refers to the form of school assessment of students, and that they do not know what schooling cycles are. Most interviewees claimed to be contrary to the continuous assessment because they believe that without annual repetition the students would be promoted without learning and would not study. It was noted that the fact of municipal teaching not be organized in cycles as it had been conceived in the initial proposal influences the opposition from parents and students about continuous assessment.

Keywords: Schooling cycles; Parents; Students.

\footnotetext{
* Doutora em Educação pela Universidade de São Paulo (USP) e Professora da Universidade Federal de São Paulo (UNIFESP). E-mail: marciajacomini@uol.com.br
} 


\section{Introdução}

Neste texto, apresentamos uma parte dos dados de uma pesquisa realizada em duas escolas da Rede Municipal de Ensino da cidade de São Paulo acerca da concepção dos pais e dos alunos sobre os ciclos e a progressão continuada. A pesquisa de campo, de caráter qualitativo, teve a duração de um ano letivo. A coleta de dados foi realizada por meio da observação do cotidiano escolar: aulas, entrada e saída dos alunos, recreios, festas, Reuniões de Pais e Mestres, Reuniões do Conselho de Escola e de entrevistas com 14 pais e 14 alunos de cada escola, totalizando 56 sujeitos.

O objetivo da pesquisa foi analisar a concepção dos pais e dos alunos sobre a organização do ensino em ciclos e a progressão continuada na Rede Municipal de Ensino de São Paulo.

Duas questões principais motivaram a realização da pesquisa: 1) a importância e a centralidade que as políticas de não-reprovação anual (organização do ensino em ciclos e progressão continuada) têm adquirido no cenário educacional brasileiro, na perspectiva da realização de uma educação de qualidade para toda a população; e 2) a carência de pesquisas que tenham como foco a análise do posicionamento dos pais e dos alunos a respeito dessas políticas.

As propostas e experiências de organização do ensino em ciclos têm sido respaldadas no pressuposto político de democratização do ensino e da aprendizagem. Isso significa que os ciclos devem favorecer a realização de um processo educativo, no qual todos os alunos se apropriem da cultura como condição para o desenvolvimento pessoal e social.

Entende-se, assim, que a organização do ensino em ciclos pressupõe mudanças tanto na compreensão do desenvolvimento e da aprendizagem como quanto no tempo e espaço escolar, no conteúdo, na metodologia, na avaliação e nas relações entre os envolvidos no processo educativo.

A progressão continuada também pode ser compreendida a partir de uma perspectiva de ruptura com o caráter seletivo da escola, ao propor o fim da reprovação anual. Mas, para isso, é necessário que a promoção esteja respaldada num conjunto de medidas que favoreçam a aprendizagem e garantam a continuidade do processo de ensino e aprendizagem, de acordo com as necessidades de cada aluno. 
O ensino municipal de São Paulo foi organizado em ciclos com progressão continuada em 1992, na gestão da prefeita Luiza Erundina, na época, filiada ao Partido dos Trabalhadores (PT). De acordo com o Regimento Comum das Escolas Municipais (RCME), "a adoção do regime de ciclos implica em nova forma de trabalho com os alunos, segundo o ritmo de seu desenvolvimento cognitivo, social e afetivo". (SÃO PAULO, 1992, p. 7). Pretendia-se, com isso, respeitar a dinâmica de aprendizagem de cada aluno, oferecendo os meios e as condições para a aprendizagem de todos:

A organização em ciclos para o Ensino Fundamental tem por objetivo assegurar ao educando a continuidade no processo ensino-aprendizagem, respeitando o seu ritmo e suas experiências de vida, adequando os conteúdos e métodos aos seus estágios de desenvolvimento. Essa nova política supõe uma renovação progressiva das práticas vivenciadas nas escolas. Implica na elaboração e na construção de novas formas de trabalho do professor, propiciando maior integração do trabalho docente, através do planejamento coletivo dos professores do mesmo ciclo. A concepção de ciclo é uma noção pedagógica estreitamente vinculada à evolução da aprendizagem de cada educando e a avaliação de seus avanços e dificuldades. (SÃO PAULO, 1992, p. 7).

Embora esses fossem os propósitos dos ciclos na cidade de São Paulo, a eleição de Paulo Maluf, para a gestão de 1993-1996, e a introdução de uma política educacional contrária aos ciclos e a à progressão continuada, fizeram com que a proposta fosse se descaracterizando, na medida em que as condições pedagógicas, organizacionais e de formação dos professores necessárias a um ensino em ciclos não foram realizadas na gestão malufista ou nas subsequentes. Assim, em 2005, quando a pesquisa de campo foi realizada, apesar da organização do ensino em ciclos constar dos regimentos escolares, o ensino se caracterizava por uma seriação com progressão continuada.

\section{Pesquisa qualitativa em educação}

Considerando-se a natureza do problema estudado - analisar as concepções e opiniões de pais e alunos sobre os ciclos e a progressão continuada na Rede Municipal de Ensino de São Paulo -, optou-se por uma pesquisa de caráter qualitativo. Entende-se que "uma das grandes postu- 
lações da pesquisa qualitativa é a de sua atenção preferencial pelos pressupostos que servem de fundamento à vida das pessoas" (TRIVIÑOS, 1987, p. 130). Assim, além de conhecer as opiniões dos pais e dos alunos sobre essa política educacional, buscar-se-á compreender os significados do conteúdo manifesto e subjacente às falas dos entrevistados.

Desse modo, as observações do cotidiano escolar, as conversas com os alunos, a observação de atividades escolares que envolvem a participação de pais e as entrevistas semi-estruturadas, com a introdução de informações e questionamentos sobre as falas dos depoentes, foram realizadas para captar significados subjacentes à opinião deles sobre a temática estudada e conhecer as explicações conscientes que sustentam tais opiniões. Entende-se que isso não contribui para uma visão unilateral, mas, ao contrário, como propõe Thiollent (1987, p. 23-24; cf. PARO, 1996, p. 25), "é justamente o questionamento que deveria superar a unilateralidade da observação do outro ao permitir uma real intercomunicação".

A seleção do grupo de pais e alunos entrevistados obedeceu ao critério de três características relacionadas à aprendizagem e à reprovação escolar: 1) aluno com baixo desempenho escolar; 2) aluno com bom desempenho escolar; e 3) aluno que já havia sido reprovado. Foram selecionados alunos do $3^{\circ}$ e $4^{\circ}$ anos do ciclo I e dos quatro anos do ciclo II. Não foram entrevistados alunos do $1^{\circ}$ e $2^{\circ}$ anos do ciclo I, por se considerar que estes são crianças muito pequenas e com pouca experiência escolar para participarem da entrevista ${ }^{2}$.

Ao compor o conjunto de sujeitos da pesquisa, teve-se a preocupação de entrevistar alunos e pais de ambos os sexos e com diferentes tipos de experiências em relação à aprendizagem e à reprovação escolar.

\subsection{Algumas características das escolas pesquisadas}

Em fevereiro de 2005, foi realizado um levantamento de instituições municipais que atendessem ao critério estabelecido para a escolha das escolas: uma escola que tivesse participação dos pais e alunos na tomada de decisão em relação ao processo educativo e outra, cujos pais e alunos não participassem de tais decisões. Esse critério atendeu a necessidade de verificação da hipótese de que a participação dos pais e dos alunos na escola pudesse influenciar o posicionamento destes a respeito da progressão continuada. 
A escola Carlota ${ }^{3}$ foi escolhida por atender ao critério de nãoparticipação dos pais e alunos nas tomadas de decisões do processo educativo. Ela se situa-se na zona sul da cidade de São Paulo e atende filhos de 1) porteiros que trabalham nos prédios da região; 2) pequenos comerciantes da classe média baixa; e 3) moradores de uma favela próxima. No ano de 2005, a escola atendeu cerca de 700 alunos no ensino fundamental regular, em dois turnos: manhã e tarde.

O funcionamento do cotidiano da escola Carlota é bastante tradicional. Quando as crianças chegam, permanecem com os responsáveis num amplo corredor ao lado das salas de informática e de apoio pedagógico, até a abertura do portão, cinco minutos antes do sinal. Elas entram, empurrando-se umas às outras, formam filas em locais previamente marcados e esperam pelos professores.

As salas de aula são identificadas por série e não por ano do ciclo. Os alunos e pais utilizam o termo "série" para referirem-se ao ano de escolarização em que o filho se encontra. A organização das carteiras na sala de aula é tipicamente tradicional: em fileiras. As aulas seguem o padrão de aulas expositivas, com maior ou menor participação dos alunos, dependendo do incentivo e da dinâmica do professor.

Em relação à participação dos pais, observou-se que estes vão à escola para serem informados sobre o desempenho dos filhos ou serem solicitados a cooperar com as atividades realizadas. Em nenhum momento observou-se a construção coletiva do processo educativo por pais, alunos e educadores.

$\mathrm{Na}$ escola Carlota foram realizadas 36 visitas, entre observação do cotidiano escolar, participação em reuniões de pais e mestres, festas e entrevistas.

A escola JK, escolhida por atender ao critério da participação de pais e alunos na construção do processo educativo, localiza-se na zona oeste oeste de São Paulo. Assim como a escola Carlota, ela atende a uma clientela diversificada. Fazem parte do corpo discente 1) filhos de funcionários da Universidade de São Paulo (USP); 2) filhos da classe média baixa; e 3) alunos que moram em cortiços e numa favela próxima à escola.

Em 2005, a escola funcionou em três turnos: ciclo II do ensino fundamental, no período da manhã, e ciclo I do ensino fundamental, no período da tarde. Havia em torno de 800 alunos matriculados. No perío- 
do noturno, funcionava a Educação de Jovens e Adultos que não fez parte desta pesquisa.

Apesar dessas semelhanças quanto à clientela, observou-se que a escola JK tem funcionamento bastante diferente da escola Carlota, em vários aspectos: a escola $\mathrm{JK}$ se encontra em processo de reorganização do currículo, dos espaços, dos tempos e das relações educadores/educandos, tendo como referência a Escola da Ponte ${ }^{4}$, em Portugal.

$\mathrm{Na}$ escola JK, os alunos não se organizam em filas para se dirigirem às salas de aula: o portão fica aberto e eles podem ocupar todo o espaço da escola nos momentos em que não estão em sala. Não há sinal para indicar troca de aula, recreio, entrada ou saída das salas de aula. Os alunos chamam os professores, a diretora, os coordenadores e demais funcionários pelo nome, sem a utilização do pronome de tratamento "senhor ou senhora", como usualmente acontece nas escolas. Os educadores e funcionários não alteram o tom da voz para falar com os alunos.

O Projeto JK, como é chamado, começou a ser implementado no início de 2004, envolvendo os $1^{\text {os }}$ anos dos ciclos I e II. A partir do $1^{\circ}$ primeiro semestre de 2005, passaram a participar do Projeto os $2^{\text {os }}$ anos dos ciclos I e II e, no $2^{\circ}$ segundo semestre do mesmo ano, os alunos dos $3^{\text {os }}$ anos do ciclo I e II. Em 2006, a nova proposta pedagógica estendeuse a todos os alunos.

A escola JK rompeu com a idéia ideia de sala de aula, tal como a conhecemos, e reestruturou o espaço físico, transformando as salas de aulas em grandes salões onde os alunos de cada ano do ciclo sentam-se em pequenos grupos e realizam suas atividades a partir de um roteiro quinzenal. O processo de ensino e de aprendizagem deixou de ser centrado em aulas expositivas e na realização de exercícios de fixação de conteúdo. Os objetivos, conceitos e conteúdos das disciplinas são previamente organizados no roteiro quinzenal e os alunos escolhem a atividade que desejam fazer em cada momento da aula. Estes contam com o apoio do livro didático e de computadores para a realização das atividades. Os professores de todas as disciplinas atendem os grupos ou alunos individualmente esclarecendo dúvidas e explicando o conteúdo.

Cada grupo de 15 alunos tem um educador tutor que acompanha, semanalmente, o desenvolvimento de suas atividades. A tutoria é um momento em que o aluno, com o auxílio do tutor, avalia seu desempenho e o envolvimento na realização das atividades do roteiro quinzenal. Os 
tutores também são responsáveis por fazer o relatório individual de seus tutorandos, o qual é entregue aos pais no final de cada semestre.

A participação dos pais e dos alunos na escola JK aproxima-se, bastante, de uma participação nos processos de elaboração e decisão relativos à atividade educativa. Porém, cabe ressaltar que esse tipo de participação não se estende à maioria dos pais.

$\mathrm{Na}$ escola JK, foram realizadas 26 visitas entre observação do cotidiano e entrevistas com pais e alunos.

\subsection{Organização do conteúdo das entrevistas em categorias temáticas}

Dados os limites deste texto, foram escolhidos dois dos nove temas analisados a partir dos dados obtidos na pesquisa de campo: 1) o conhecimento dos pais e dos alunos sobre como está organizado o ensino municipal da cidade de São Paulo; e 2) a opinião dos pais e dos alunos sobre os ciclos e a progressão continuada.

O conteúdo das entrevistas foi organizado em categorias temáticas. De acordo com Bardin (2004, p. 111), "a categorização é uma operação de classificação de elementos constitutivos de um conjunto, por diferenciação e, seguidamente, por reagrupamento segundo o gênero (analogia), com os critérios previamente definidos". Para organizar as categorias temáticas, classificaram-se os elementos que constituíram as falas dos entrevistados, a partir do critério semântico, tendo em vista os temas propostos no roteiro da entrevista e outros que foram espontaneamente expressos pelos entrevistados.

\section{Conhecimento dos entrevistados sobre como está organizado o ensino municipal}

O conhecimento dos pais sobre a organização do ensino municipal nas duas escolas pesquisadas restringe-se, muitas vezes, ao fato de saberem que não há reprovação em todos os anos letivos.

Ao serem questionados se sabiam como está formalmente organizado o ensino municipal, todos os pais da escola Carlota responderam que não e apenas dois da escola JK disseram que sim e fizeram referência aos ciclos. Uma entrevistada da escola Carlota fez referências ao ciclo durante a entrevista, embora tivesse dito não saber direito como este fun- 
cionava. Apesar de não saberem exatamente o que são ciclos e progressão continuada, os pais percebem que a escola funciona de forma diferente.

Quadro 1. 0 que os pais dizem saber sobre os ciclos e progressão continuada

\author{
A.Escola Carlota \\ as notas são NS - S - P \\ sei que não pode reprovar \\ reprova por falta todos os anos ou na $4^{\mathrm{a}}$ ou $8^{\mathrm{a}}$ série por desempenho \\ sei que só retém na $8^{\mathrm{a}}$ série \\ na reunião foi dito que eles não reprovam por aprendizagem, só for falta

\section{B. Escola JK} \\ antigamente não passava se não soubese, agora vão passando \\ escutei que não tem mais reprovação \\ conheço como série e progressão continuada \\ tenho conhecimento da aprovação imediata \\ 0 que eu sei é que até a $4^{\mathrm{a}}$ série não reprova
}

A representação que os pais de ambas as escolas têm da nova organização do ensino diz respeito a uma percepção e a um conhecimento fragmentado sobre como ocorrem a promoção e a reprovação na escola.

Para os pais, a mudança que ocorreu na escola está relacionada à atribuição de conceitos no lugar de notas e ao fim da reprovação anual. Nenhum pai fez referência a qualquer mudança na forma de organização do currículo escolar.

Questionados sobre a organização do ensino no município de São Paulo, os alunos de ambas as escolas disseram saber que só existe reprovação por desempenho no $4^{\circ}$ ano dos ciclos I e II (eles falaram $4^{\mathrm{a}} \mathrm{e}$ $8^{a}$ séries). Nem todos sabiam que há reprovação por falta em todos os anos. Optamos por não fazer um quadro com as manifestações dos alunos em relação a essa questão porque ele apresentaria apenas a frase "não há mais reprovação".

Não haver reprovação por desempenho todos os anos é o principal conhecimento que os alunos das duas escolas têm a respeito da organização do ensino municipal. Se considerarmos a proposta de ciclos e progressão continuada elaborada em 1992, o conhecimento, tanto dos alunos quanto dos pais, é bastante parcial e, num certo sentido, distorcido em relação ao significado original da proposta. 


\section{Opinião dos entrevistados sobre os ciclos e a progressão continuada}

A terceira questão do roteiro da entrevista tinha como objetivo conhecer a opinião dos pais e dos alunos sobre os ciclos e a progressão continuada. No entanto, diante das respostas em relação à questão anterior, com a maioria dos entrevistados dizendo não saber como o ensino municipal está organizado, ou apenas saber que não há reprovação anual, foram necessárias algumas explicações sobre os ciclos e a progressão continuada, especialmente aos pais, antes de estes responderem à questão. Porém, essas informações não mudaram a dinâmica dos entrevistados ao falarem somente sobre a "não-reprovação".

Assim, frente ao desconhecimento do significado do ensino em ciclos com progressão continuada, os entrevistados expressaram suas opiniões basicamente sobre esta, mas referindo-se a ela como não-reprovação anual. Percebe-se que os termos "ciclos" e "progressão continuada" não fazem parte do vocabulário dos entrevistados. No lugar de progressão continuada, pais e alunos usam os termos "não-reprovação anual" ou "não reprova mais".

Os pais da escola Carlota foram mais contundentes no posicionamento a favor da reprovação anual. Eles demonstraram estar convencidos de que a reprovação é necessária no processo ensino-aprendizagem. Ao contrário, metade dos pais entrevistados da escola JK abordou a reprovação anual como uma medida que merece ser analisada cuidadosamente, pois esta não trará, necessariamente, benefício ao aluno. No entanto, demonstraram preocupação com um sistema de ensino que promova os alunos sem que eles tenham realizado aprendizagens básicas. Parece haver, entre os pais da escola JK, uma tendência a repensar o papel da reprovação no processo ensino-aprendizagem, embora não se atribua, de forma conclusiva, a postura desses pais, em relação à reprovação escolar, à experiência que estão vivenciando com a nova organização curricular e pela forma diferenciada de participação nas atividades escolares.

Os alunos da escola Carlota também foram mais enfáticos na defesa da reprovação anual. 
Quadro 2. Motivos apresentados pelos pais para haver reprovação anual na escola

\author{
A. Escola Carlota \\ para 0 aluno estudar \\ porque não adianta passar se 0 aluno não sabe nada \\ os alunos não se esforçam porque sabem que só reprova por falta \\ a reprovação é uma forma dos alunos se interessarem mais \\ a reprovação contribui para um ensino bem melhor \\ se tivesse reprovação todo ano os alunos estudariam desde 0 início do ano \\ as crianças que não têm um bom desempenho devem ser reprovadas \\ se não reprovar, os sitema de ensino estará apoiando as crianças a não estudarem \\ para 0 aluno não ir para a outra série sem saber \\ a reprovação incentiva a criança a aprender mais

\section{B. Escola JK} \\ a não-reprovação desestimula 0 aluno a estudar \\ a reprovação é uma punição porque 0 aluno não estudou \\ a reprovação é para os alunos não passarem sem saber \\ sem reprovação os alunos não estudam porque sabem que vão passar do mesmo jeito \\ quando tinha reprovação eles tinham medo e estudavam mais \\ não reprovar é ruim porque 0 aluno não estuda, vai mal e no final do ano ele passa \\ as crianças não estudam porque sabem que vão passar \\ deve ter reprovação todo ano para a criança se interessar e estudar
}

Os motivos apresentados pelos pais da escola Carlota para justificar a defesa da reprovação anual estão vinculados a três idéias ideias básicas: 1) forma de pressão ou estímulo para os alunos estudarem; 2) melhor qualidade de ensino; e 3) impedir que o aluno seja promovido sem saber o conteúdo daquele ano letivo. O pensamento de que a reprovação é fundamental para garantir que os alunos estudem foi o mais presente nas falas dos pais. Parece haver uma crença de que, se houver reprovação anual, os alunos estudarão e, se não houver, não estudarão.

Também esteve presente na fala dos pais a preocupação com o fato de o aluno ser promovido sem ter aprendido os conteúdos escolares, produzindo uma situação de pouca aprendizagem durante o período de escolarização, apesar da conclusão do ensino fundamental. Os pais acreditam também que a reprovação pode garantir uma melhor qualidade de ensino porque a escola não certificaria alunos que não atingissem os objetivos estabelecidos.

Os pais da escola JK que defendem a reprovação anual, assim como a maioria dos pais da escola Carlota, argumentaram que a reprovação é importante para incentivar os alunos a estudarem e para impedir a promoção quando os alunos não aprendem os conteúdos estabelecidos pela escola. Além disso, consideram-na como uma forma de punição aos 
alunos que não estudam. Entendem que, com o recurso da reprovação, a escola cumpriria o papel de enquadrar os alunos num conjunto de regras sociais que devem ser seguidas.

Quadro 3. Motivos apresentados pelos alunos para haver reprovação anual na escola

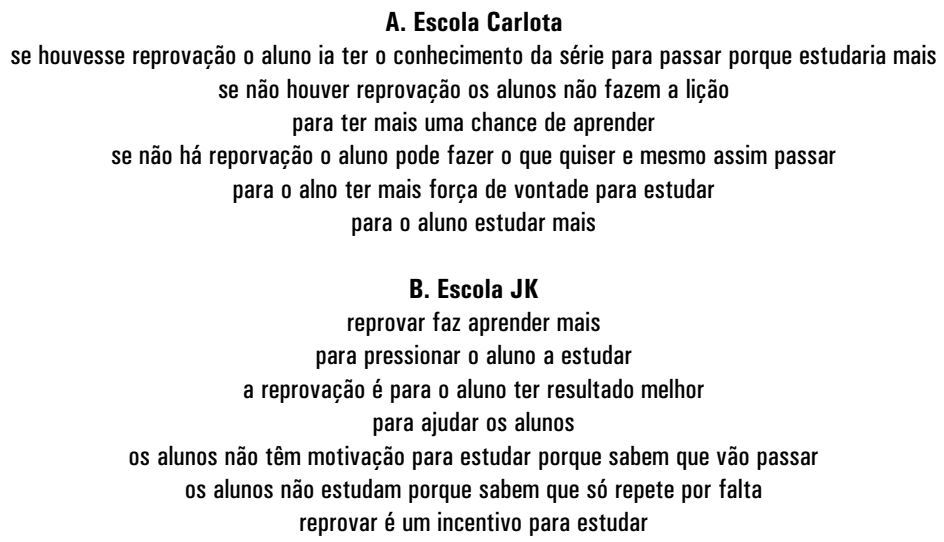

A argumentação de que a reprovação é uma forma de pressionar ou incentivar os alunos a estudar se repete na fala dos alunos de ambas as escolas. Eles apresentam a reprovação como uma nova chance de aprender e acreditam que, se não há reprovação, os alunos não estudam ou não fazem lição. A reprovação aparece como uma medida para impedir que os alunos façam o que quiserem na escola.

Quadro 4. Motivos apresentados pelos pais para não haver reprovação anual

\section{A. Escola Carlota}

a reprovação é ruim para 0 aluno e a família porque fere 0 sentimento da criança se a criança for reprovada ela não vai ter chance de aprender

\section{B. Escola JK}

quando 0 aluno é reprovado ele pode parar de estudar

Na opinião das duas mães da escola Carlota que concordaram com a progressão continuada, a reprovação é ruim porque prejudica a auto-estima e atrapalha a aprendizagem da criança. Esses dois motivos são complementados pela possibilidade de a criança abandonar a escola quando é reprovada, argumento apresentado pela mãe da escola JK. Para essas 
três mães, a escola não deve reprovar porque isso não traz nenhum benefício ao aluno.

Quadro 5. Motivos apresentados pelos alunos para não haver reprovação anual

\author{
A. Escola Carlota \\ porque tem que aprender tudo de novo \\ porque se separa dos colegas \\ B. Escola JK \\ quem não aprendeu tudo deve ser promovido e ter esforço \\ porque 0 aluno sente que é um perdido na vida
}

Os dois alunos da escola Carlota que defenderam a progressão continuada apresentaram dois problemas característicos da reprovação: 1) o fato de o aluno, ao repetir determinada série, ter de estudar as coisas que ele já estudou no ano anterior; e 2) o fato de este aluno ter de separar-se dos colegas. Para eles, esses motivos justificam a não-reprovação anual. Os alunos da escola JK falaram 1) do direito de ser promovido e ter reforço para aprender o que não aprendeu no ano anterior; e 2) do sentimento de menos-valia que a reprovação pode causar ao aluno.

Quadro 6. Motivos apresentados pelos pais que concordam com a reprovação anual (em termos)

\title{
A. Escola JK
}

se quisermos tirar a reprovação é necessário um trabalho para garantir que todos aprendam a escola deve ajudar a criança e só reprovar se ela não aprende mesmo se a escola não ajuda os alunos ela não deve reprovar depende da situação de cada, um às vezes é bom reprovar para ele aprender mais para não ter reprovação é necessário um trabalho que garanta a aprendizagem

Somente pais da escola JK fizeram ressalvas à reprovação anual. Eles não afirmaram ser totalmente a favor da progressão continuada porque consideram que a escola ainda falha em sua tarefa de ensinar. Além disso, para eles, o fim da reprovação levaria à certificação de alunos semianalfabetos. No entanto, concordam que o fim da reprovação se faz necessário para garantir o direito à educação para todos. Um aspecto importante nessas considerações é a afirmação de que, se a escola não ajuda os alunos, ela não deve reprová-los. Se, em falas anteriores, a reprovação era justificada pela pouca aprendizagem do aluno, na fala dessa mãe, 
ela é desautorizada quando a escola não ajuda os alunos. De certa forma, essa mãe chama a atenção para o papel e a função da escola na aprendizagem das crianças.

Quadro 7. Motivos apresentados pelos alunos que concordam com a reprovação anual (em termos)

\section{A. Escola Carlota}

às vezes reprovar não adianta porque 0 aluno continua não aprendendo

\section{B. Escola JK}

a não-reprovação pode ser ruim só se 0 aluno for passando sem saber

nem sempre reprovar faz 0 aluno estudar mais

a reprovação é ruim porque a gente se separa do grupo

Os alunos de ambas as escolas que não concordam totalmente com a reprovação anual questionaram a afirmação de que o aluno estuda e aprende mais se for reprovado ou se houver reprovação anual. Talvez, as experiências vivenciadas nas escolas tenham levado tais alunos a começarem a questionar o papel atribuído à reprovação pela maioria de seus colegas entrevistados. Se existem casos em que repetir um ano letivo pode levar o aluno a empenhar-se mais e melhorar seu desempenho escolar, isso parece não ser a regra, uma vez que a reprovação é recorrente no Brasil. Parece que isso começa a ser percebido por alguns alunos.

\section{A reprovação escolar nas falas dos pais e dos alunos}

Embora o objetivo inicial deste estudo fosse analisar a concepção dos pais e dos alunos sobre os ciclos e a progressão continuada na Rede Municipal de Ensino de São Paulo, os dados da pesquisa de campo não permitiram tal análise, porque, como visto no item anterior, os entrevistados não falaram sobre os ciclos, impossibilitando, assim, qualquer análise nesse sentido.

Uma hipótese levantada durante a pesquisa para explicar o desconhecimento dos pais e dos alunos sobre os ciclos é o fato de o ensino municipal caracterizar-se atualmente por uma "seriação com progressão continuada" no decorrer dos anos dos chamados ciclos. Como houve uma descaracterização da proposta de 1992, pode-se dizer que os entrevistados não estão tendo uma experiência de ensino organizado em ciclos. 


\subsection{Justificativas dos entrevistados para se contraporem à progressão continuada}

As duas principais justificativas dos pais e alunos para se opoerem à progressão continuada foram: 1) os alunos são promovidos sem terem aprendido os conteúdos escolares de forma adequada; 2) se não houver reprovação anual, os alunos não estudam.

A primeira justificativa apresentada pelos pais e alunos da Rede Municipal de São Paulo também foi verificada entre os pais de alunos da Escola Plural ${ }^{5}$ de Belo Horizonte, conforme mostra pesquisa de Ramon Correa de Abreu (2002).

No grupo de famílias predominantemente contrárias ao Programa Escola Plural, a avaliação que os pais fazem é a de que os filhos não estão aprendendo e/ou não estão aprendendo os conteúdos que consideram como realmente úteis e importantes. (ABREU, 2002, p. 150)

A maioria dos entrevistados, da Rede Municipal de São Paulo, disse ser contrária à progressão continuada porque acredita que sem a reprovação anual os alunos serão promovidos sem saber.

Também acreditam que, ao repetirem a "série", terão nova chance de aprender o que não aprenderam no ano em que foram reprovados. Assim, no imaginário de muitos pais e alunos, a reprovação aparece diretamente vinculada a uma segunda e "garantida" oportunidade de aprender.

Eles veem a reprovação como algo necessário à escolarização e, em certo sentido, bom "pro aluno aprender melhor. $\mathrm{O}$ aluno perde o ano porque não aprendeu nada, então vai tentar de novo pra ver se aprende".

As explicações de muitos pais sobre a reprovação escolar reafirmam a idéia ideia de que ela contribui para o aluno aprender mais porque ele irá rever todo o conteúdo no ano seguinte. De acordo com o depoimento de uma mãe, "a reprovação é ótima, porque não adianta você passar de ano se você não entendeu nada". Para essa mãe a reprovação seria uma forma de ampliar o tempo para o aluno realizar a aprendizagem, quando ele não consegue fazê-la no período de um ano letivo. "Eu acho que a reprovação ajuda, porque o que você não aprendeu nesse ano você volta tudo de novo".

$\mathrm{Na}$ perspectiva apresentada pelos entrevistados, a reprovação anual propicia melhor aprendizagem porque impede os alunos, que não 
atingiram os objetivos escolares, de prosseguirem, e lhes dá nova oportunidade de aprendizagem.

Além do argumento da aprendizagem, muitos pais e alunos de ambas as escolas expressaram sua oposição à progressão continuada, dizendo que, se não houver reprovação anual, os alunos não estudam. Eles acreditam que a reprovação pressiona os alunos a estudarem e que estes respondem positivamente a isso.

Uma das mães entrevistadas defendeu a reprovação anual como algo bom para a escola e para os alunos porque estes não se esforçam mais como antigamente. Assim como outros entrevistados, ela considera que a progressão continuada tem sido prejudicial ao aluno porque este se sente desestimulado a estudar, na medida em que todos serão promovidos, independentemente do esforço de cada um.

Eu acho que [a reprovação] seria boa pra escola e pros alunos também, porque era um meio de eles se interessarem mais. Ou estuda pra passar e chega o final do ano e é aprovado, ou então fica difícil, porque eles sabem que só vão reprovar de quatro em quatro anos, eles não se esforçam como antes.

A ideia da necessidade da reprovação escolar, seja para evitar que alunos com pouca aprendizagem sejam promovidos porque se não houver a pressão da reprovação eles não estudam, também foi verificada em um estudo sobre a rede estadual paulista. Em pesquisa sobre relações família e escola, no contexto da progressão continuada, a autora constatou que "dentre as famílias entrevistadas nenhuma concordava com a nova política educacional porque eliminava a reprovação entre as séries" (MAGALHÃES, 2004, p. 404)

Essa ideia esteve presente na fala da maioria dos entrevistados da Rede Municipal de São Paulo. No entanto, durante as entrevistas, alguns começaram a questionar a veracidade de tal crença. Questionados se a ameaça da reprovação leva efetivamente os alunos a estudarem, uma parte dos entrevistados concluiu que não necessariamente. Eles deram exemplos, pautados em suas experiências, em que a ameaça da reprovação não havia provocado nenhuma mobilização nos alunos para estudarem mais.

Assim, as duas justificativas usadas pelos entrevistados para defenderem a reprovação anual parece não estar correspondendo à representação que pais e alunos têm sobre os efeitos da reprovação escolar. Em 
relação à aprendizagem, eles mesmos verificaram que, apesar de terem sofrido uma ou mais reprovações, os alunos continuam com baixo desempenho escolar. Em relação à pressão para estudar e ter melhor aprendizagem, os entrevistado também têm verificado que, geralmente, isso não acontece. Mas, como se trata de uma crença, enquanto não tiverem a oportunidade de confrontá-la com a realidade de forma reflexiva e crítica, tenderão a continuar afirmando-a, mesmo em contradição com suas experiências.

\subsection{A defesa da reprovação escolar não é unânime entre pais e alunos}

Embora a maioria dos entrevistados, considerando as duas escolas, tenha manifestado opinião contrária à progressão continuada, alguns pais e alunos opuseram-se claramente à reprovação anual ou consideraram ser necessário analisar cada situação. Em outras palavras, alguns pais e alunos não compartilharam da opinião de que a reprovação é sempre necessária.

Isso demonstra que, embora hegemônica, a oposição à progressão continuada não é unânime. Isso possibilita a convivência de posições diferentes, o que pode contribuir para instigar reflexões que tragam novos elementos e informações para a discussão. No entanto, é necessário que sejam criados espaços para tal.

Entre os argumentos usados para defender a progressão continuada estão os prejuízos causados pela reprovação à auto-estima da criança e à evasão escolar. Para uma das entrevistadas, a reprovação é muito nociva à auto-estima da criança e do adolescente:

Eu acho que a reprovação é ruim pro aluno e pra família. Pro aluno porque ele já leva o nome de reprovado, por muito vadio que ele seja, por muito semvergonha que ele seja, aquilo fere o sentimento dele, então a escola não reprovando, ajudando como os professores hoje ajudam, eu acho que eles se sentem mais fortes. Porque chega em casa, os irmãos falam: Ah! Cala a boca, você é reprovado, você não tem que dar palpite.

Alguns alunos também disseram que a reprovação é prejudicial à auto-estima do aluno. Opinaram que o reforço escolar deveria ser uma alternativa à reprovação, ou seja, a escola deveria investir em medidas pedagógicas que oferecessem melhores condições de aprendizagem para 
não reprovar os alunos com baixo desempenho: “O aluno que repete já tem aquela auto-estima baixa, então pensa... Perdi o ano... Agora que se dane, alguns falam... Então, às vezes piora... Acho que deveria ter uma alternativa, que é o reforço."

Magalhães (2004) também encontrou alunos que, apesar de afirmarem não concordar com a progressão continuada, "consideravam a repetência ruim" (p. 405). De acordo com a autora, os alunos reivindicavam mais oportunidades de recuperação e reforço durante o ano letivo, contrapondo-se à proposta de recuperação nas férias, em vigor na rede estadual paulista naquele momento.

Uma mãe fez considerações sobre as contradições da reprovação anual. Embora inicialmente tenha dito que a reprovação era uma forma de pressionar os alunos a estudarem, admitiu que ela pode desestimular o aluno, levando-o a não querer frequentar a escola: “[...] se ele ficar sendo reprovado aqui, ele pode ser desestimulado e não querer mais ver uma classe, ou uma sala de aula mais pra frente".

Além do sentimento de inferioridade e incapacidade que a reprovação pode provocar no aluno e na família, ela foi apresentada por alguns entrevistados como causa da evasão. Para uma das mães entrevistadas, é bom não haver reprovação todo ano porque, após duas reprovações, seu filho pararia de estudar, se fosse reprovado novamente. Ao se referir à progressão continuada, disse: "Eu achei até bom não ter reprovação todo ano, porque, no caso, ele ia parar de estudar".

Apesar de serem minoria, os entrevistados que defenderam a progressão continuada o fizeram com base numa compreensão dos males que a reprovação provoca, especialmente, para os alunos. Pode-se dizer que, de alguma forma, esses pais e alunos têm refletido a realidade escolar numa perspectiva diferente da maioria e trazido para a discussão outra forma de compreender as políticas de não-reprovação anual.

\section{Considerações finais}

Os dados desta pesquisa indicam que a proposta de organização do ensino em ciclos, tal como foi concebida e implantada na Rede Municipal de São Paulo, no ano de 1992, último ano da gestão de Luiza Erundina, não foi desenvolvida nos governos subsequentes, levando a 
uma descaracterização dos ciclos. Isso explica, em parte, o desconhecimento dos ciclos por parte dos entrevistados.

Assim, a verificação de que o conhecimento dos pais e dos alunos sobre a organização do ensino municipal de São Paulo restringe-se à informação de que não há reprovação anual, reforça a ideia de os pressupostos políticos e pedagógicos da proposta original não estarem presentes na organização e nas práticas escolares, a descaracterização dos ciclos e reafirma a necessidade da proposta inicial ser retomada. dos pressupostos da proposta original serem retomados.

Uma vez que a oposição dos entrevistados à progressão continuada é, em parte, consequência de uma experiência de progressão continuada desvinculada de um ensino em ciclos, pode-se supor que mudanças pedagógicas favoráveis a efetivos processos de aprendizagem poderiam contribuir para a diminuição das resistências às políticas de não-reprovação anual.

Isso sugere que as políticas educacionais devem ser pensadas sob duas perspectivas: mudanças na materialidade das escolas e na mentalidade tradicional de pensar a educação escolar.

Numa perspectiva dialética, as mudanças na materialidade do processo educativo devem favorecer a introdução de novas concepções de educação, que, por sua vez, ajudarão na construção de uma nova práxis educativa.

Nesse contexto, tanto os ciclos quanto a progressão continuada devem ser entendidos como parte de um processo mais amplo e complexo de universalização da educação e de garantia de padrões de qualidade. 


\section{REFERÊNCIAS}

ABREU, Ramon Correa de. Familias de camadas populares e Programa Escola Plural: as lógicas de uma relação. 2002. Dissertação (Mestrado em Educação) - Faculdade de Educação, Universidade Federal de Minas Gerais, Belo Horizonte, 2002.

ALMEIDA JÚNIOR, Antonio Ferreira de. E a escola primária? São Paulo: Nacional, 1959. BARDIN, Laurence. Análise de conteído. 3. ed. Lisboa: Edições 70, 2004.

BRASIL. Lei $n^{\circ}$ n. 4.024, de 20 de dezembro de 1961. Estabelece as diretrizes e bases da educação nacional. Diário Oficial [da] República Federativa do Brasil, Brasília, DF, 27 dez. 1961.

BRASIL___ Lei ${ }^{\circ}$ 5.692, de 11 de agosto de 1971. Fixa diretrizes e bases para o ensino de $1^{\circ}$ e $2^{\circ}$ graus. Diário Oficial [da] República Federativa do Brasil, Brasília, DF, 12 ago. 1971.

BRASIL___. Lei no 9.394, de 20 de dezembro de 1996. Estabelece as diretrizes e bases da educação nacional. Diário Oficial [da] República Federativa do Brasil, Brasília, DF, 23 dez. 1996.

BRASIL . Ministério da Educação. Instituto Nacional de Estudos e Pesquisas Educacionais Anísio Teixeira. Matrícula por forma de organização e dependência administrativa, Brasil e São Paulo (Estado e município) - 2004. Brasília, 2004.

BRASIL . Ministério da Educação. Secretaria de Educação Fundamental. Parâmetros curriculares nacionais. Brasília: MEC/SEF, 1997.

CANÁRIO, Rui; MATOS, Filomena; TRINDADE, Rui (Org.). Escola da Ponte: defender a escola pública. Lisboa: Profedições, 2004

MAINARDES, Jefferson. Reinterpretando os ciclos de aprendizagem. São Paulo: Cortez, 2007. MAGALHÃES, Cleidilene Ramos. Escola e famílias: mundos que se falam? Um estudo no contexto da implementação da progressão continuada. 2004. Tese (Doutorado em Educação)- Centro de Educação e Ciências Humanas, Universidade Federal de São Carlos, São Carlos, 2004.

MÉSZÁROS, István. O poder da ideologia. São Paulo: Boitempo, 2004.

PACHECO, José. Quando eu for grande quero ir à primavera e outras histórias. São Paulo: Suplegraf, 2003.

PARO, Vitor Henrique. Por dentro da escola pública. 2. ed. São Paulo: Xamã, 1996.

PARO, Vitor Henrique . Reprovação escolar: renúncia à educação. São Paulo: Xamã, 2001.

SÃO PAULO (SP). Secretaria Municipal de Educação. Regimento comum das escolas municipais de São Paulo. São Paulo, 1992.

SOUSA, Sandra Zákia Lian; BARRETO, Elba Siqueira de Sá. Estado do conbecimento ciclos e progressão escolar (1990-2002). Relatório final. Faculdade de Educação, Universidade de São Paulo, São Paulo, 2004.

THIOLLENT, Michel J. M. Crítica metodológica, investigação social e enquete operária. 5. ed. São Paulo: Polis, 1987.

TRIVIÑOS, Augusto Nibaldo Silva. Introdução à pesquisa em ciências sociais: a pesquisa qualitativa em educação. São Paulo: Atlas, 1987. 


\section{NOTAS}

1 Este artigo foi produzido a partir de minha tese de doutorado, defendida em abril de 2008, na Faculdade de Educação da USP, com o título: Reprovação escolar na opinião de pais e alunos: um estudo sobre os ciclos e a progressão continuada na Rede Municipal de Ensino de São Paulo. Trata-se da análise de uma parte dos dados da pesquisa de campo.

2 Quando a pesquisa foi realizada, no ano de 2005, o ensino fundamental tinha duração de 8 anos. A Lei $n^{\circ}$. 11.274/2006 determinou a ampliação do ensino fundamental de 8 para 9 anos.

3 Para preservar a identidade das escolas, os nomes apresentados neste trabalho são fictícios.

4 Para saber mais sobre a Escola da Ponte, ler: CANÁRIO; MATOS; TRINDADE (2004); PACHECO (2003).

5 A proposta de Escola Plural, em Belo Horizonte, foi implantada em 1994 e previa a organização do ensino em ciclos e a progressão continuada durante os anos dos ciclos.

Recebido: 05/05/2009

Aprovado: 07/07/2010

Contato:

Universidade Federal de São Paulo

Rua Prof. Arthur Riedel, 275

Jardim Eldorado

Diadema - SP

CEP 09972-270 